Journal of Biotechnology and Strategic Health Research

\author{
Review / Derleme
}

http://dergipark.org.tr/tr/pub/bshr

\title{
COVID-19 Hastalığında Görülen Ağız Bulguları
}

\author{
Oral Symptoms in Covid-19 Disease
}

\section{Merve Köseoğlu' ${ }^{1}$ (D) Mustafa Altındiş ${ }^{2}$}

${ }^{1}$ Sakarya Üniversitesi Diş Hekimliği Fakültesi Protetik Diş Tedavisi, Adapazarı, Sakarya

${ }^{2}$ Sakarya Üniversitesi Tip Fakültesi Tibbi Mikrobiyoloji Anabilim Dalı, Adapazarı/Sakarya

ORCID ID: Merve Köseoğlu https://orcid.org/0000-0001-9110-9586, Mustafa Altındiş https://orcid.org/0000-0003-0411-9669

*Sorumlu Yazar / Corresponding Author: Merve Köseoğlu, e-posta / e-mail: mervekoseoglu89@gmail.com

Geliş Tarihi / Received : 30-11-2021 Kabul Tarihi / Accepted: 06-12-2021 Yayın Tarihi / Online Published: 30-12-2021

Köseoğlu M, Altındiş M. COVID-19 Hastalığında görülen ağız bulguları, J Biotechnol and Strategic Health Res. 2021; 5(3):178-184

$\ddot{O ̈ z}_{z}$

Sars- Cov-2 virüsü, tüm dünyada hızla yayılım göstermiş, Mart 2020 tarihinden itibaren ise, Dünya Sağlık Örgütü (DSÖ) tarafından, dünya genelinde pandemi ilan edilmiştir. COVID-19' un genel semptomları olarak ateş, yorgunluk, öksürük, kas ağrısı, nefes darlığı, baş ağrısı, boğaz ağrısıdır ve pnömoni görülebilmektedir. COVID-19'da en sık görülen ağız semptomu ise hastaların \% 45 'inde görülen tat bozukluklarıdır. Ayrıca hastalarda, herpetiform ve aft benzeri lezyonlar, kandidiyazis ve Kawasaki benzeri lezyonlar gibi çeşitli oral mukoza lezyonları görülebilmektedir. Bu derleme çalışmasının amacı, COVID-19 hastalı̆̆ında görülen ağız bulgularını incelemektir.

Anahtar COVİD-19; Ağız bulguları; Oral mukoza lezyonları; Tat bozuklukları

Kelimeler

\begin{tabular}{l}
\hline Abstract \\
SARS Cov-2 virus has spread rapidly all over the world, and since March 2020, it has been declared a worldwide pandemic by the World Health \\
Organization (WHO). The general symptoms of COVID-19 are fever, fatigue, cough, myalgia, dyspnea, headache, sore throat and pneumonia. \\
The most common oral symptom in COVID-19 is taste disorders, which is seen in 45\% of patients. In addition, various oral mucosal lesions such \\
as herpetiform and aphthous-like lesions, candidiasis and Kawasaki-like lesions can be observed in patients. The purpose of this review study is \\
to examine the mouth findings seen in COVID-19 disease.
\end{tabular}

Keywords COVID-19; Oral manifestations; Oral mucosa lesions; Taste disorders 


\section{INTRODUCTION}

Dünya Sağlık Örgütü (DSÖ) tarafından Aralık 2019'da, Çin'in Wuhan şehrinde, etiyolojik durumu bilinmeyen pnömoni vakalarının sayıca arttığı rapor edilmiştir. Ocak 2020 tarihinde ise, daha önce insanlarda tespit edilmemiş yeni bir koronavirüs türü olan SARS Cov-2'nin hastalığın etkeni olduğu belirtilmiştir. Bu hastalığın adı COVİD-19 olarak kabul edilmiştir ve DSÖ tarafından 30 Ocak'ta COVİD-19 salgınının tüm dünya ülkeleri için önemli bir halk sağlığı acil durumu olduğu belirtilerek, salgının ortaya çıktığı Çin'in dışında 113 ülkede de virüs kaynaklı vakaların görülmesi nedeniyle bu yeni durum, pandemi olarak tanımlanmıştır. Ülkemizde ise ilk COVİD-19 vakası 11 Mart 2020'de görülmüştür. ${ }^{1}$

COVİD-19' un genel semptomları ateş, yorgunluk, öksürük, kas ağrısı, nefes darlığı, baş ağrısı ve boğaz ağrısıdır. ${ }^{2-6}$ Şiddetli vakalarda hastalarda pnömoninin klinik belirtilerine ilişkin raporlar bulunmaktadır. ${ }^{3}$ COVİD-19 salgınının başlangıcında, COVİD-19 'un oral tutulumunun olmadığ 1 ve bu özelliği ile diğer viral ekzantemlerden ayırt edici olduğu düşünülmüştür. Ancak, daha sonra SARS Cov-2 virüsü hastaların tükürüğünde tespit edilmiştir ve tükürükten yapilan ters transkriptaz-polimeraz zincir reaksiyonu (RT-PCR) testinin, nazofaringeal testten bile daha hassas bir test olabileceği belirtilmiştir. Ayrıca, SARS Cov-2 için bilinen bir reseptör olan Anjiyotensin dönüştürücü enzim 2 (ACE 2) reseptörünün, oral mukozada, özellikle dilin dorsumunda, bukkal mukozada ve damaktaki tükürük bezlerinde bulunduğu belirlenmiştir. ${ }^{7}$

COVİD-19 hastalarında görülen oral lezyonlar, enfeksiyonun doğrudan bir belirtisi, sistemik tutulmanın bir belirtisi veya tedavide kullanılan ilaçların yan etkisi olabilir. ${ }^{8}$ COVİD-19 hastalarında görülen oral lezyonlar arasında, tat alma bozukluğu, spesifik olmayan oral ülserasyonlar, diş eti iltihapları, peteşi veya kandidiyazis gibi fursatçı enfeksiyonlar vardır., ${ }^{9,10}$

\section{Tat Bozuklukları}

Tat bozuklukları, COVID-19'un ilk tanımlanan oral semptomudur. ${ }^{7}$ Tat bozuklukları ile COVİD-19 semptomları arasında pozitif korelasyon bulunmuştur. Hastalığı hafif/ orta şiddette geçirenlerde ve kadın hastalarda tat bozukluklarının daha sık görüldügü belirlenmiştir. ${ }^{9}$ Tat bozuklukları çalışmalarda, disguzi, hipoguz ve aguzi olarak sınıflandırılmıştır. ${ }^{11} 2021$ yılı itibarıyla güncel bir meta analiz çalışmasının sonuçlarına göre, tat alma bozukluklarının genel prevalansının \%45, disguzinin \%38, hipoguzinin $\% 35$ ve aguzinin \%24 olduğu belirlenmiştir. Tat bozuklukları, coğrafi bölgelere göre incelendiğinde ise, Kuzey Amerikalı hastaların \%53' ünde, Avrupalıların \%50' sinde ve Asyalıların \%27’ sinde gözlemlenmiştir. ${ }^{9}$

COVİD-19 hastalarında tat bozukluklarının sebebi olarak farklı görüşler belirtilmiştir. Bunlardan ilki, SARS Cov-2 virüsünün periferal sinir sistemini etkilediği ve tat tomurcukları da kraniyal sinirler tarafından inerve edildiğinden, yeni koronavirüsün tat alma duygusunu bu yolla etkilediği şeklindedir. ${ }^{12,13}$ İkinci teori, SARS Cov-2'nin sialik asit gibi esansiyel tükürük müsin bileşenlerini bağlaması sonucunda tat parçacıkları bozunmasının hızlanması ve rahatsız edici tat hissinin oluşmasıdır. ${ }^{14-16}$ Ayrıca, dilde yüksek oranda ACE2 reseptörünün bulunmas1 ${ }^{7}$ ve bu reseptörün SARS Cov-2 virüsü ile etkileşimi, tat alma duyusunun bozulmasına yol açabilmektedir. ${ }^{12,17}$ Ek olarak, ACE2 blokeri olan ilaçların, G protein-bağlı reseptörler ve sodyum kanalı inaktivasyonu ile tat duyusunda bozulmaya yol açtığı bildirilmiştir. ${ }^{16,18,19}$

\section{Kserostomi ve Halitozis}

COVİD-19 hastalarının cevapladığı anketlerden edilen bilgilere göre, ${ }^{20-24}$ kserostominin COVİD-19'un sistemik semptomlarının başlangıcından daha önce ortaya çıktığ ve ortalama prevalansının, metaanaliz sonuçlarına göre \%43 olduğu belirlenmiştir. ${ }^{11}$ COVİD-19 hastalarında halitozis görülme oranı ile ilgili metaanaliz çalışması görülmemekle birlikte, bir çalışmada 573 katılımcıdan \%10’unda görüldüğü bildirilmiştir. ${ }^{20}$ 
Araştırmacıların bir kısmı, COVİD-19 hastalarındaki kserostomiye, tedavide kullanılan ilaçların, burun tıkanıklığı ve ağız solunumunun, beslenme yetersizliği, diyabet, pandemi veya uzun süreli hastaneye yatışa bağlı olarak görülen anksiyete ve stresin neden olduğunu belirtmişlerdir. ${ }^{20,21,24,25}$ Bununla birlikte, bazı çalışmalarda, virüsün periferik ve santral sinir sistemi üzerindeki potansiyel nöroinvazivliği vurgulanmıştır. ${ }^{26-28}$ Ağız kuruluğu, ağız kokusu ve tat bozuklukları gibi semptomların COVİD-19'la ilişkisi hala tartışmalı olsa da, SARS Cov-2'nin, tükürük bezlerini ve tat tomurcuklarını etkilemesi sonucunda, tükürügün akışında ve kalitesinde bozulma, tat almada bozukluklar, ağız kuruluğu ve halitosise neden olduğu öne sürülmüştür..$^{21,28-31}$

\section{Parotitis ve Sialadenit}

Literatürde yer alan 5 çalışmada, COVİD-19'la enfekte toplam 22 hastada tükürük bezlerinde inflamasyon rapor edilmiştir. 21 hastada parotid bezi tek taraflı etkilenirken, 1 hastada parotid ve submandibular tükürük bezleri etkilenmiştir. Parotitis semptomları, SARS Cov-2 enfeksiyonunun klinik belirtilerinden önce veya COVID-19 enfeksiyonuyla aynı zamanda gözlenmiştir. ${ }^{32-34}$ Literatürde, parotitisin patofizyolojisinin daha detaylı olarak araştırılması önerilmekle birlikte, SARS Cov-2'in tükürük bezlerini etkilemesi sonucunda, ${ }^{29}$ enfekte tükürük bezlerinin, doğrudan viral parotisise, doku iltihabı veya koenfeksiyonlara daha duyarlı olduğu belirtilmiştir. ${ }^{34,35}$

\section{Periodontal Hastalıklar}

Kronik ve çok faktörlü enfeksiyöz kökenli bir hastalık olan periodontitis, dişin destek dokularında kayba ve olumsuz sistemik etkilere sahiptir. Periodontitisin, kronik obstrüktif akciğer hastalığı, diyabet, obezite, hipertansiyon, kardiyovasküler hastalıklar, kanser ve yaşlanma olmak üzere pek çok durum ve hastalıklarla ilişkili olduğu belirlenmiştir. $^{36-38}$

Periodontal cep içerisinde, çeşitli virüslerin bulunduğu ispatlanmıştır. ${ }^{39}$ Hafif ve orta dereceli periodontitis vaka- larında bile virüslerin çoğalması, tükürüğe karışarak ağız boşluğuna ulaşması veya periodontal kapiller ağı vasitasıyla sistemik hareket edebilmesi için, ülsere periodontal cep epiteli elverişli bir rezervuar görevi görebilmektedir ve SARS Cov-2 virüsü için uygun ekolojik alan olabilmektedir. ${ }^{40}$ Ayrıca, periodontitiste üretilen pro-inflamatuar sitokinler ve doku yıkım ürünleri, dolaşım sistemine salınmakta ve bireyin sistemik inflamasyon yükünü arttırmaktadır. Bu kronik sistemik inflamasyon da periodontitisli bireylerde, COVID-19'un şiddetini arttırmasına neden olabilmektedir. ${ }^{41,42}$ Şiddetli COVİD-19 enfeksiyonu sırasında görülen sitokin fırtınasının, periodontitisin sitokin ekspresyon profili ile CRP, interlökin 6 gibi birçok ortak bileşeni olduğu gözlenmektedir. ${ }^{43} \mathrm{Bu}$ durum, periodontitis ile COVİD-19 enfeksiyonu ve komplikasyonları arasında bir bağlantı olabileceğini düşündürmektedir. ${ }^{44}$

Bakteriyel süper enfeksiyonlar, COVİD-19'daki mortalite ve morbidite üzerinde son derece etkilidir. COVİD-19'u şiddetli geçiren hastaların çoğunun klinik tablosunda, bakteriyel pnömoni geçirdikleri belirlenmiştir. ${ }^{45}$ Ağız boşluğu ve akciğerlerin, patojenik, simbiyotik ve komensal organizmaları barındıran mikrobiyotaları vardır. ${ }^{46}$ Ağız boşluğu ve akciğerler arasında var olan mikrobiyal denge, hastalık var olduğunda, mikroorganizmaların lehine değişebilir ve ilerleyen dönemde akciğer hasarına yol açabilir. Prevotella intermedia, Porphyromonas gingivalis, Fusobacterium nucleatum gibi ağız içi patojen bakteriler, sekresyonlarla beraber aspire edilebilmekte ve alt solunum yolu enfeksiyonuna yol açabilmektedir. ${ }^{47}$ Periodontal rahatsızlıkların, akciğer ile ağız arasında bakteri değiş tokuşunu, solunum yolu enfeksiyonlarını ve post-viral bakteri komplikasyonlarını arttırabilen önemli risk faktörü oldukları belirtilmiştir. ${ }^{48}$

Literatürde, periodontal hastalıklarla COVİD-19 arasındaki olası bağlantıyı inceleyen çalışmalardan birinde, periodontitisli COVID-19 hastalarında, kanda beyaz kan hücreleri, D-dimer ve CPR seviyelerinin, periodontal olarak sağlıklı hastalardan daha yüksek olduğu ve periodon- 
titisin, COVİD-19'da görülen, yoğun bakıma alınma, solunum cihazına bağlanma, hatta ölümle sonuçlanan ciddi komplikasyonların oluşma riski ile önemli derecede ilişkili olduğu belirtilmiştir. ${ }^{49}$ Başka bir çalışmada ise, COVİD-19 hastalarında, diş eti kanaması ve plak birikiminin daha fazla olduğu, kötü ağız hijyeni ile ilişkili şiddetli periodontitisin, SARS Cov-2 enfeksiyonunun ağırlaşmasına neden olabileceği belirtilmiştir. ${ }^{50}$ Ayrıca, COVİD-19 tedavisinde rutin ve deneysel olarak kullanılan ilaçların da ağızda birtakım problemlere yol açmasının muhtemel olduğu, bu nedenle, COVİD-19'un akut dönemini atlatan hastalarda, özellikle post akut dönemde ağızdaki mikrobiyal yükü azaltmak için ağız sağlığının korunmasının ve ağız bakımının takibe alınmasının önem taşıdığı belirtilmiştir. ${ }^{44}$

Literatürde, COVİD-19 şüphesi olan ve ateş, submandibular lenfadenopati, ağız lezyonları ve ağız kokusu ile başvuran, 35 yaşında bir kadın bireyle ilgili bir vaka raporu mevcuttur. Ağıı lezyonlarının ağrılı, yaygın eritemli ve interpapiller alanları nekroz olan ödemli diş eti şeklinde olduğu ve nekrotizan periodontal hastalığın, COVİD-19'la birlikte bakteriyel koenfeksiyondan (özellikle prevotella intermedia) kaynaklandığ ve lezyonların 5 gün içerisinde iyileştiği belirtilmiştir. ${ }^{51}$

\section{Oral Mukoza Lezyonları}

COVİ-19 hastalarında, oral mukozada, ülser, erozyon, bül, vezikül, püstül, fissürlü veya depapilla dil, makül, papül, plak, pigmentasyon, beyazımsı alanlar, nekroz, peteşi, şişlik, eritem ve spontan kanama gibi semptomlar gözlenmiştir. Oral mukoza lezyonları, dil, dudak mukozası, damak, diş eti, bukkal mukoza, orofarenks ve tonsillerde görülmüştür. Vakaların \%68'inde, oral lezyonlarda ağrı, yanma hissi veya kaşıntı gibi semptomlar gözlenmiştir. Oral lezyonlar, neredeyse her iki cinsiyette de eşit oranda görülmektedir. Oral lezyonlar, sistemik semptomların başlamasından önce veya semptomlar başladıktan sonra görülebilmektedir. En uzun latent periyoda sahip oral lezyonların ise Kawasaki benzeri lezyonlar olduğu belirlenmiştir. ${ }^{52}$ Oral lezyonların, hastalarda tat ve koku kaybı ile simultane görüldüğü, daha şiddetli ve yaygın oral lezyonların ise hastalığın daha ağır seyrettiği durumlarda ve yaşlı hastalarda gözlemlendiği bildirilmiştir. ${ }^{21}$

Kötü ağız hijyeni, fırsatçı enfeksiyonlar, stres, hastalarda diabetes mellitus, immunsupresyon gibi rahatsızlıkları varlığı, entübe edilen hastalarda entübasyona sekonder olarak gelişen travma, vasküler bozulma ve COVİD-19’a karşı gelişen hiper inflamatuvar reaksiyonların, COVİD-19 hastalarında oral lezyon gelişimi için predispozan faktörler olduğu belirtilmiştir. Oral mukoza lezyonlarının tedavisinde, etiyolojiye bağlı olarak; klorheksidin gargara, nistatin, oral flukonazol, topikal veya sistemik kortikosteroidler, sistemik antibiyotikler, sistemik asiklovir, yapay tükürük ve fotobiyomodülasyon tedavisi uygulanabilir. ${ }^{52}$

COVİD-19 hastalarında, aft benzeri lezyonlar, eritemli çoklu sı̆̆ ülserler ve sarı-beyaz psödomembranlar olarak keratinize ve keratinize olmayan mukozada görülmüştür. Aft benzeri lezyonlar, sistemik semptomlarla aynı anda ya da 2-10 gün latent süresinin ardından görülebilmektedir., ${ }^{83-55}$ Nekroze olmayan aft benzeri lezyonlar, hafif COVİD-19 enfeksiyonlu ve daha genç yaştaki hastalarda gözlenirken; nekroze olan aft benzeri lezyonlar ise immünsupresyonu olan ve COVİD-19 enfeksiyonunu ağır geçiren yaşlı hastalarda daha sık gözlenmiştir. Bu lezyonların iyileşme süresinin 5 ila 15 gün olduğu ${ }^{56}$ ve oral lezyonların iyileşmesinin sistemik hastalığın iyileşmesi ile paralel olduğu belirlenmiştir. ${ }^{8}$

Herpetiform lezyonlar, COVİD-19 hastalarında, çoklu, ağrılı, tek taraflı, etrafı eritematöz, yuvarlak sarımsı gri ülserler şeklinde hem keratinize ve hem de keratinize olmayan mukozada gözlenmiştir. Bu lezyonlar, sistemik semptomların ortaya çıkmasından önce, sistemik semptomlarla aynı zamanda veya bunlardan sonra ortaya çıkabilmektedir. COVİD-19 ile ilişkili stres ve immünsupresyonun sekonder herpetik gingivostomatitin ortaya çıkış nedeni olduğu düşünülmüştür. ${ }^{8,56-59}$ 
COVİD-19 hastalarında, ülseratif veya eroziv lezyonların, dil, sert damak ve labial mukoza üzerinde, düzensiz sınırları olan ağrılı lezyonlar olarak ortaya çıktığı belirlenmiştir. Lezyonlar, sistemik semptomların başlamasından önce ya da sonra ortaya çıkabilmektedir. Bu lezyonların görüldüğü hastalarda yapılan HSV-1 ve HSV-2 testleri negatif çıkmıştır. İlaç erüpsiyonu, vaskülit veya COVİD-19'a sekonder olarak gelişen trombotik vaskülopatinin, ülseratif ve eroziv lezyonların gelişme nedenleri olduğu düşünülmüş̧ür. ${ }^{60-65}$

COVİD-19 hastalarında, Kawasaki benzeri hastalıkta; şelitis, glossitis, eritematöz ve şişmiş dil gibi oral lezyonlar görülmüştür. Bu hastalarda, sistemik semptomların ortaya çıkması ile oral veya kutanöz semptomların başlaması arasındaki uzun latent sürenin varlığı, bağışıklık sisteminin gecikmiş hiperaktivasyon yanıtı ve cilt ve ağız mukozasinda bulunan virüsün direkt etkisinden ziyade, akut inflamatuar sitokinlerin ikincil salınımından kaynaklandığı düşünülmüştür..$^{66-73}$

Angina bülloza benzeri lezyonlar, COVİD-19 pozitif teşhisi konmuş iki vakanın dil ve damağında, spontan kanaması olmayan asemptomatik eritematöz kabarcıklar şeklinde görülmüştür. ${ }^{74}$ Eritema multiforme benzeri lezyonlar, kabarcıklar, deskuamatif gingivitis, eritematöz maküller, erozyonlar ve hemorajik kabuklu ağrılı şelitis şeklinde gözlenmiştir. Lezyonların sistemik semptomların başlamasından 7 ila 24 gün sonra ortaya çıktığı ve 2 ila 4 hafta sonra iyileştiği belirlenmiştir. ${ }^{75,76}$

Çeşitli çalışmalarda, COVİD-19 hastalarında, dil, dudak mukozası, sert damak ve orofarenkste eritematöz maküller, papüller ve plaklar görüldüğü bildirilmiştir. Doğrulanmış veya şüphelenilen COVİD-19 vakalarında, bireylerin dil sırtı, diş eti ve damaklarında beyaz ve kırmızı lekeler veya plaklar rapor edilmiştir. Uzun süreli antibiyotik tedavisine bağlı gelişen kandidiyazisin, genel sağlığın bozulmasının ve ağız hijyenindeki düşüşün bu lezyonların nedeni olabileceği düşünülmüşsür. ${ }^{2,9,77}$ Birkaç çalışmada ise, alt dudak, damak ve orofarenks mukozasında peteşi- ler rapor edilmiştir. Sadece peteşi lezyonlarının görüldügü vakalarda latent sürenin, hem peteşi hem de maküler lezyonların görüldüğü vakalara göre daha kısa olduğu belirtilmiştir. COVİD-19 enfeksiyonuna veya reçete edilen ilaçlara bağlı olarak gelişen trombositopeninin, peteşilerin olası nedenlerinden olduğu öne sürülmüştür. ${ }^{2,78,79}$

\section{SONUÇ}

Literatürdeki klinik çalışmalarda, COVİD-19'un oral semptomları sıklıkla belirtilmemekle birlikte, rapor edilen az sayıda çalışma göz önüne alındığında, tat değişikliklerinin $45 \%$ prevalans ile en sık görülen ağız bulgusu olduğu anlaşılmıştır. Ayrıca, tat bozukluklarının, hastalığı hafif/ orta şiddette geçiren, kadın COVİD-19 hastalarında daha sık görüldüğü belirtilmiştir. ${ }^{9}$

Ağız hijyeni yetersizliğinin, fırsatçı enfeksiyonların, bireylerin diğer sistemik rahatsızlıklarının, sekonder veya entübasyona bağlı travmanın ve COVİD-19’a bağlı artmış enflamatuvar cevabın, COVID-19 hastalarında oral mukoza lezyonlarının gelişiminde predispozan faktör olduğu belirtilmiştir. Ayrıca, yaşlı ve hastalığın klinik seyiri ağır olan COVİD-19 hastalarında, oral mukoza lezyonlarının oluşma riskinin daha fazla olduğu ve bu bireylerde daha ciddi oral mukoza lezyonlarının görüldüğü bildirilmiştir. ${ }^{52}$

\section{Açıklamalar}

Çalışmayı maddi olarak destekleyen kişi/kuruluş yoktur ve yazarların herhangi bir çıkar dayalı ilişkisi yoktur. 


\section{Kaynaklar}

1. Sağlık Bakanlığı (2020). https://COVID19.saglik.gov.tr/ Eklenti/38597/0/COVİD-19 rehberi genel bilgiler epidemiyoloji ve tani pdf, Türkiye Cumhuriyeti Sağlık Bakanlığı, Halk Sağlığı Genel Müdürlüğü, COVID-19 Rehberi, Genel Bilgiler Epidemiyolojı ve Tanı Bölümü, s;5-6, Güncellenme Tarihi:3.09.2020.

2. Corchuelo J, Ulloa FC. Oral manifestations in a patient with a history of asymptomatic COVID-19: Case report. Int J Infect Dis 2020;100:154-7.

3. Xu J, Chu M, Zhong F, et al. Digestive symptoms of COVID-19 and expression of ACE2 in digestive tract organs. Cell Death Discov 2020;6:1-8.

4. Martín Carreras-Presas C, Amaro Sánchez J, López-Sánchez AF, et al. Oral vesiculobullous lesions associated with SARS Cov-2 infection. Oral Dis 2021;27:710-2.

5. Tapia ROC, Labrador AJP, Guimaraes DM, et al. Oral mucosal lesions in patients with SARS Cov-2 infection. Report of four cases. Are they a true sign of COVID-19 disease? Spec Care Dent 2020;40:555-650

6. Chary E, Carsuzaa F, Trijolet JP, et al. Prevalence and recovery from olfactory and gustatory dysfunctions in COVID-19 infection: A prospective multicenter study. Am J Rhinol Allergy 2020;34:686-93.

7. Seirafianpour F, Sodagar S, Pour Mohammad A, et al. Cutaneous manifestations and considerations in COVID-19 pandemic: a systematic review. Dermatol Ther 2020; 33:13986.

8. Dos Santos JA, Normando AGC, Carvalho da Silva RL, et al. Oral mucosal lesions in a COVID-19 patient: New signs or secondary manifestations? Int J Infect Dis 2020;97:326-

9. Dos Santos JA, Normando AGC, da Silva RLC, et al. Oral manifestations in patients with COVID-19: A living systematic review. J Dent Res 2021;100:141-54.

10. Aggarwal S, Garcia-Telles N, Aggarwal G, et al. Clinical features, laboratory characteristics, and outcomes of patients hospitalized with coronavirus disease 2019 (COVID-19): early report from the United States. Diagnosis 2020;7:91-96.

11. Dos Santos JA, Normando AGC, Carvalho da Silva RL, et al. Oral Manifestations in Patients with COVID-19: A 6-Month Update. J Dent Res 2021; doi: 10.1177/00220345211029637.

12. Finsterer J, Stollberger C. Causes of hypogeusia/hyposmia in SARSCoV2 infected patients. J Med Virol 2020; 92:1793-1794.

13. Kinnamon SC, Cummings TA. Chemosensory transduction mechanisms in taste. Annu Rev Physiol 1992; 54:715-731.

14. Milanetti E, Miotto M, Di Rienzo L, et al. In-Silico Evidence for a Two Receptor Based Strategy of SARS Cov-2. Front Mol Biosci 2021; doi: 10.3389/fmolb.2021.690655.

15. Pushpass RG, Pellicciotta N, Kelly C, et al. Reduced salivary mucin binding and glycosylation in older adults influences taste in an in vitro cell model. Nutrients 2019;11:2280.

16. Vaira LA, Salzano G, Fois AG, et al. Potential pathogenesis of ageusia and anosmia in COVID-19 patients. Int Forum Allergy Rhinol 2020; 10:1103-1104.

17. Nataf $S$. An alteration of the dopamine synthetic pathway is possibly involved in the pathophysiology of COVID-19. J Med Virol 2020; 92:1743-1744.

18. Tsuruoka S, Wakaumi M, Nishiki K, et al. Subclinical alteration of taste sensitivity induced by candesartan in healthy subjects. Br J Clin Pharmacol 2004;57:807-812.

19. Unnikrishnan D, Murakonda P, Dharmarajan TS. If it is not cough, it must be dysgeusia: differing adverse effects of angiotensin-converting enzyme inhibitors in the same individual. J Am Med Dir Assoc 2004;5:107-110.

20. Abubakr N, Salem ZA, Kamel AHM. Oral manifestations in mild-tomoderate cases of COVID-19 viral infection in the adult population. Dent Med Probl 2021; 58:7-15.

21. Biadsee A, Biadsee A, Kassem F, et al. Olfactory and oral manifestations of COVID-19: sex-related symptoms - a potential pathway to early diagnosis. Otolaryngol Head Neck Surg 2020; 163:722-728.

22. Chen L, Zhao J, Peng J, et al. Detection of SARS Cov-2 in saliva and characterization of oral symptoms in COVID-19 patients. Cell Prolif 2020;53:12923.

23. Fantozzi PJ, Pampena E, Di Vanna D, et al. Xerostomia, gustatory and olfactory dysfunctions in patients with COVID-19. Am J Otolaryngol 2020;41:102721.

24. Sinjari B, D’Ardes D, Santilli M, et al. SARS Cov-2 and oral manifestation:an observational, human study. J Clin Med 2020; 9:3218.

25. Tsuchiya H. Oral symptoms associated with COVID-19 and their pathogenic mechanisms: A Literature Review. Dent J 2021;9:32.

26. Freni F, Meduri A, Gazia F, et al. Symptomatology in head and neck district in coronavirus disease (COVID-19): a possible neuroinvasive action of SARS Cov-2. Am J Otolaryngol 2020;41:102612.

27. Reza-Zaldívar EE, Hernández-Sapiéns MA, Minjarez B, et al. Infection mechanism of SARS COV-2 and its implication on the nervous system. Front Immunol 2021;11:621735.

28. Saniasiaya J. Xerostomia and COVID-19: unleashing Pandora’s box. Ear Nose Throat J 2021;100:139.
29. Belchior Fontenele MN, Pedrosa MDS. Xerostomia and taste alterations in COVID-19. Ear Nose Throat J 2021;100:186-187.

30. Da Silva Pedrosa M, Sipert CR, Nogueira FN. Altered taste in patients with COVID-19: the potential role of salivary glands. Oral Dis 2021; 27:798-800.

31. Riad A, Kassem I, Hockova B, et al. Halitosis in COVID-19 patients. Spec Care Dentist 2021; 41:282-285

32. Lechien JR, Chetrit A, Chekkoury-Idrissi Y, et al. Parotitis-like symptoms associated with COVID-19, France, March-April 2020. Emerg Infect Dis 2020; 26: 2270-2271.

33. Riad A, Kassem I, Badrah M, et al. Acute parotitis as a presentation of COVID-19? Oral Dis 2020; doi:10.1111/odi.13571

34. Fisher J, Monette DL, Patel KR, et al. COVID-19 associated parotitis. Am J Emerg Med 2021;39:254.e1-254.e3

35. Capaccio P, Pignataro L, Corbellino M, et al. Acute parotitis: a possible precocious clinical manifestation of SARS Cov-2 infection? Otolaryngol Head Neck Surg 2020;163:182-183.

36. Slots J. Periodontitis: facts, fallacies and the future. Periodontol 2000 2017;75:7-23.

37. Bozoglan A, Ertugrul AS, Taspınar M, et al. Determining the relationship between atherosclerosis and periodontopathogenic microorganisms in chronic periodontitis patients. Acta Odontol Scand 2017;75:233-42.

38. Pitones-Rubio V, Chávez-Cortez EG, Hurtado- Camarena A, et al. Is periodontal disease a risk factor for severe COVID-19 illness? Med Hypotheses 2020;144:109969.

39. Cappuyns I, Gugerli P, Mombelli A. Viruses in periodontal disease-a review. Oral Dis 2005;11:219-9.

40. Badran Z, Gaudin A, Struillou X, et al. Periodontal pockets: A potential reservoir for SARS Cov-2? Med Hypotheses 2020;143:109907.

41. Herrera D, Serrano J, Roldán S, et al. Is the oral cavity relevant in SARS Cov-2 pandemic? Clin Oral Investig 2020;24:2925-30.

42. Sampson V. Oral hygiene risk factor. Br Dent J. 2020;228:569.

43. Sahni V, Gupta S. COVID-19 \& Periodontitis: The cytokine connection. Med Hypotheses $2020 ; 144: 109908$

44. Bozoğlan A, Yılmaz Bozoğlan M. Periodontal hastalık, SARS Cov-2 ve ilaçlar. Emingil G, editör. Diş Hastalıkları ve COVID-19. 1. Baskı. Ankara: Türkiye Klinikleri; 2020. p.75-82.

45. Sampson V, Kamona N, Sampson A. Could there be a link between oral hygiene and theseverity of SARS Cov-2 infections? Br Dent J 2020;228:971-5.

46. Toraldo DM, Conte L. Influence of the lung microbiota Dysbiosis in chronic obstructive pulmonary disease exacerbations: the controversial use of corticosteroid and antibiotic treatments and the role of Eosinophils as a disease marker. J Clin Med Res 2019;11:667675 .

47. Scannapieco FA, Genco RJ. Association of periodontal infections with atherosclerotic and pulmonary diseases. J Periodontal Res 1999;34:340-5.

48. Scannapieco FA. Position paper of The American Academy of Periodontology: periodon tal disease as a potential risk factor for systemic diseases. J Periodontol 1998;69:841-50.

49. Marouf N, Cai W, Said KN, et al. Association between periodontitis and severity of COVID-19 infection: A case-control study. J Clin Periodontol 2021;48: 483-91.

50. Anand PS, Jadhav P, Kamath KP, et al. A case-control study on the association between periodontitis and coronavirus disease (COVID-19). J Periodontol 2021; doi:10.1002/ JPER.21-0272

51. Patel J, Woolley J. Necrotizing periodontal disease: oral manifestation of COVID-19. Oral Dis 2021;27:768-9.

52. Iranmanesh B, Khalili M, Amiri R, et al. Oral manifestations of COVID-19 disease: A review article. Dermatol Ther 2021;34:14578.

53. Putra BE, Adiarto S, Dewayanti SR, et al. Viral Exanthem with "pin and needles sensation" on extremities of COVID-19 patient. Int J Infect Dis 2020;96:355-358.

54. Malih N, Hajinasrollah G, Zare M, et al. Unexpected presentation of COVID-19 in a 38-year-old male patient: a case report. Case Rep Dermatol 2020;12:124-131.

55. Dominguez-Santas M, Diaz-Guimaraens B, Fernandez-Nieto D, et al. Minor aphthae associated with SARS Cov-2 infection. Int J Dermatol 2020; 59:1022-3.

56. Aghazadeh N, Homayouni M, Sartori-Valinotti JC. Oral vesicles and acral erythema: report of a cutaneous manifestation of COVID-19. Int J Dermatol 2020;59:1153-4.

57. Kammerer T, Walch J, Flaig M, et al. COVID-19 associated herpetic gingivostomatitis. Clin Exp Dermatol 2021;46:174-6.

58. Martín Carreras-Presas C, Amaro Sánchez J, López-Sánchez AF, et al. Oral vesiculobullous lesions associated with SARS Cov-2 infection. Oral Dis 2021;27:710-2.

59. Indu S. Multiple oral ulcerations-an initial manifestation of COVID 19 infection: a personal experience. J Oral Maxillofac Pathol 2020;24:227-9.

60. Sakaida T, Isao T, Matsubara A, et al. Unique skin manifestations of COVID-19: is drug 
J Biotechnol and Strategic Health Res. 2021;5(3):178-184

KÖSEOĞLU, ALTINDİş, Covid Ağız Bulguları

eruption specific to COVID-19? J Dermatol Sci 2020; 99:62-64.

61. Soares CD, de Carvalho RA, de Carvalho KA, et al. Letter to editor: oral lesions in a patient with COVID-19. Med Oral Patol Oral Cir Bucal 2020;25:563-564.

62. Ansari R, Gheitani M, Heidari F, et al. Oral cavity lesions as a manifestation of the novel virus (COVID-19): a letter-to-editor. Oral Dis 2021; 27:771-2.

63. Singh C, Tay J, Shoqirat N. Skin and mucosal damage in patients diagnosed with COVID-19: a case report. J Wound Ostomy Continence Nurs 2020;47:435-8.

64. Chaux-Bodard AG, Deneuve S, Desoutter A. Oral manifestation of COVID-19 as an inaugural symptom? J Oral Med Oral Surg 2020;26:18.

65. Ciccarese G, Drago F, Boatti M, et al. Oral erosions and petechiae during SARS Cov-2 infection. J Med Virol 2021; 93:129-132.

66. Labé P, Ly A, Sin C, et al. Erythema multiforme and Kawasaki disease associated with COVID-19 infection in children. J Eur Acad Dermatol Venereol 2020; 34:539-41.

67. Verdoni L, Mazza A, Gervasoni A, et al. An outbreak of severe Kawasaki-like disease at the Italian epicentre of the SARS Cov- 2 epidemic: an observational cohort study. Lancet 2020; 395:1771-8.

68. Jones VG, Mills M, Suarez D, et al. COVID-19 and Kawasaki disease: novel virus and novel case. Hosp Pediatr 2020;10:537-40.

69. Mazzotta F, Troccoli T, Caselli D, et al. Acral rash in a child with COVID-19. Eur J Pediat Dermatol 2020;30:79-82.

70. Chérif MY, de Filette JM, André S, et al. Coronavirus disease 2019-related Kawasaki-like disease in an adult: a case report. JAAD Case Rep 2020;6:780-2.
71. Chiotos K, Bassiri H, Behrens EM, et al. Multisystem Inflammatory Syndrome in Children During the Coronavirus 2019 Pandemic: A Case Series. J Pediat Infect Dis Soc 2020;9:393-8.

72. Chiu JS, Lahoud-Rahme M, Schaffer D, et al. Kawasaki disease features and myocarditis in a patient with COVID- 19. Pediatr Cardiol 2020;41:1526-8

73. Pouletty M, Borocco C, Ouldali N, et al. Paediatric multisystem inflammatory syndrome temporally associated with SARS Cov-2 mimicking Kawasaki disease (Kawa-CO VID-19): a multicentre cohort. Ann Rheum Dis 2020;79:999-1006.

74. Cruz Tapia RO, Peraza Labrador AJ, Guimaraes DM, et al. Oral mucosal lesions in patients with SARS Cov-2 infection. Report of four cases. Are they a true sign of COVID-19 disease? Spec Care Dentist. 2020;40:555-60.

75. Olisova OY, Anpilogova EM, Shnakhova LM. Cutaneous manifestations in COVID-19: a skin rash in a child. Dermatol Ther 2020; 33:13712.

76. Jimenez-Cauhe J, Ortega-Quijano D, Carretero-Barrio I, et al. Erythema multiforme-like eruption in patients with COVID-19 infection:clinical and histological findings. Clin Exp Dermatol 2020; 45:892-5.

77. Díaz Rodríguez M, Jimenez Romera A, Villarroel M. Oral manifestations associated with COVID-19. Oral Dis 2020; doi: 10.1111/odi.13555

78. Jimenez-Cauhe J, Ortega-Quijano D, de Perosanz-Lobo D, et al. Enanthem in patients with COVID-19 and skin rash. JAMA Dermatol 2020;156:1134-6

79. Cebeci Kahraman F, Caskurlu H. Mucosal involvement in a COVID- 19-positive patient: a case report. Dermatol Ther 2020;33:13797 